\title{
Operation of a Device Regulating Flow in a Steep Slope Channel
}

\author{
[ G. Ciaravino, C. Ciaravino ]
}

\begin{abstract}
This paper studies a flow regulation device, whose operation does not fully comply with the theoretical simplifications underlying the usual design standards for this type of structure. In particular, a flow regulation device consisting of two side weirs with a discharge rate very close to the maximum flow coming from upstream is studied on a physical model. The device is located in the pipe of a steepslope swiss-section sewer, just upstream of a flow measurement section comprising a rectangular-section venturi. The theoretical analysis and tests carried out on the experimental installation in both normal and critical conditions have identified solutions that, despite their specific characteristics, may provide indications of a more general nature.
\end{abstract}

Keywords-flow regulation device, side weirs, steep-slope channel, theoretical-experimental testing.

\section{Introduction}

Sewers that are used as drains for both rainwater and sewage are generally equipped with devices that can regulate flow discharge during flood events or divert sewage towards treatment plants. In the latter case, structures are often fitted with orifices near their bottom, for instance leaping weirs and baffled weirs [1], but these generally lead to problems of management and maintenance (specifically, cleaning the orifice) as they are constantly in use. This drawback can be avoided by fitting the flow regulation device with a side weir covered by a grill so that the solid material transported in the flow can be sent to the treatment plant. Maintenance (cleaning the grill) is simpler in this case as the weir is not constantly diverting the flow. However, if the flow to be diverted is close to the maximum flow from upstream, the operation of the device may differ somewhat from the hypotheses regulating the classic theory for the design of this type of structure [2,3]. In the latter theoretical framework, the kinematic field in a weir is characterised as two superimposed flows: one gradually variable in a longitudinal direction parallel to the weir crest, the other transverse and essentially orthogonal to the weir crest. It is also hypothesised that the transverse section has a practically horizontal free-water surface near the crest and, as a result, pressure distribution is hydrostatic. The weir discharge is normally evaluated using the same laws regulating discharge from frontal weirs. Finally, it is generally acknowledged that the total head $\mathrm{H}$ is constant

Giulio Ciaravino

Full Professor, University of Naples Federico II, Italy along the weir crest provided this is not excessively long and the channel is not very steep: consequently, the design standards encounter further problems in the case of steepslope channels or if there is a hydraulic jump near the weir.

It is not uncommon, therefore, in structures of this kind (although this problem is actually common to a number of other types of hydraulic works) for the theoretical conditions to differ considerably from those encountered in the structure, with the result that original design solutions outside the theoretical framework are often adopted. In actual fact, such eventualities are part of the attraction of engineering, as the engineer frequently has to tackle new and constantly changing problems and to identify novel and unique prototypes. Wherever possible, good design practices call for studies to be conducted on models before the prototype itself is set up, especially when dealing with works of major technical or economic importance. This paper reports a study carried out on an experimental installation regarding the design of a flow regulation device for a large sewer, whose characteristics cannot be fully encompassed by the classic sizing theories mentioned above, nor by more recent studies [4-16].

\section{The flow regulation device}

The experimental installation used in this paper is made up of a flow regulation device with side weirs whose discharge rate is very close to that of the maximum flow from upstream. In particular, the study was carried out with a theoretical analysis and through different experimental phases conducted on an installation (Fig.1) making up the physical model (1:17.5 scale) of a prototype that comprises twin side weirs (whose length has to be defined) located in a pipe (Fig.1, Sec. A-A e Sec. C-C) downstream from a Swiss-section sewer (Fig.1, Sec. B-B) and just upstream of a flow measurement section comprising a rectangular-section venturi (Fig.1, Sec. D-D). As this sewer has a bottom slope $\mathrm{i}_{\mathrm{F}}=0.0044$ and a maximum flow rate $\mathrm{Q}_{\mathrm{MM}}=50 \mathrm{~m}^{3} / \mathrm{sec}$ (referred to the prototype), it is clearly a steep-slope channel. Therefore, upstream from the measurement section we can expect the flow to change from a supercritical (rapid) flow to a subcritical (tranquil) flow through a hydraulic jump. The pipe between the Swiss-section sewer and the measurement section also serves to mark the limit of the hydraulic jump. The device has the following characteristics (referring to the prototype):

- Height of the Swiss-section sewer $h_{C}=4.20$ m (Fig.1, Sec. B-B);

Weir crest $\mathrm{Y}_{\mathrm{S}}=1.25 \mathrm{~m}$ from the bottom line (Fig.1, Sec.C-C), such as to allow the free passage of a maximum flow of $\mathrm{Q}_{\mathrm{IM}}=5 \mathrm{~m}^{3} / \mathrm{sec}$;

- Length of the section in which to fit a single weir $\mathrm{L}_{\mathrm{S}}=10.00 \mathrm{~m}$ (Fig. 1, Sec. A-A and Sec. C-C), such as to allow the discharge of a maximum flow $\mathrm{Q}_{\mathrm{SM}}$ (to be verified); 
Proc. of the Fourth International Conference on Advances in Civil, Structural and Environmental Engineering - ACSEE 2016. Copyright (C) Institute of Research Engineers and Doctors. All rights reserved. ISBN: 978-1-63248-114-6 doi: 10.15224/ 978-1-63248-114-6-31

Width of the control section $\mathrm{L}_{\mathrm{VC}}=2.40 \mathrm{~m}$ (Fig.1, Sec. D-D), such as to enable a maximum downstream discharge $\mathrm{Q}_{\mathrm{VM}}$ (to be verified);

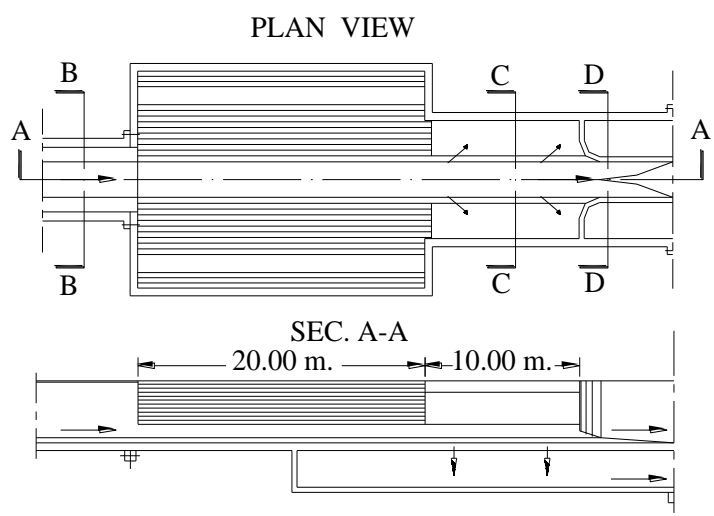

SEC. B-B - SWISS-SECTION SEWER

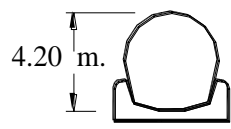

SEC. C-C - SIDE WEIRS

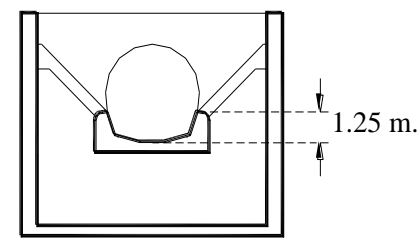

SEC. D-D - FLOW MEASUREMENT SECTION

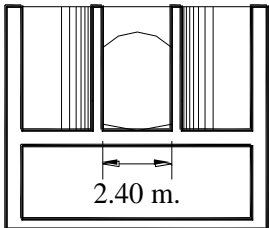

Figure 1. Experimental installation.

\section{Considerations and preliminary experimental tests}

The first tests conducted with the highest flow rates have confirmed how a hydraulic jump occurs in the proximity of the flow regulation device (downstream from the measurement section where the flow is extremely unstable) [17]. The irregularity of the flow and the uncertainties that this creates in determining the coefficients of discharge $\mu$ and of the water surface profiles on the weirs not only make an effective verification of the sizing of the structure impossible, but they also suggest the need to carry out experimental tests in successive phases. Thus, a preliminary phase aimed to identify the law for varying the total head downstream of the weir in the measurement section, determining the discharge scale of the venturi with the weir completely closed $[18,19]$. In a subsequent phase, with the measurement section closed, we verified weir operation for flows $Q_{S}=Q_{M}-Q_{V}$ (i.e. supplying an upstream flow $Q_{M}$ equal to the flow to be discharged $\mathrm{Q}_{\mathrm{S}}$, with downstream flow $\mathrm{Q}_{\mathrm{V}}=0$ ). In a final phase we conducted an overall test on the device in real operating conditions. It is clear that this approach simplified flow measurement through the individual devices in the various experimental phases. Analysis of the experimental tests with the weirs in operation may be preceded by theoretical considerations based on the classic hypotheses of steady flow, gradually varied flow, hydrostatic pressure distribution and constant total head $\mathrm{H}$ for the flow arising at the weir. In particular, we can fix:

- the total head $\mathrm{H}_{M}$ in the section upstream from the weirs for every flow $\mathrm{Q}_{\mathrm{M}}$;

- the total head $\mathrm{H}_{\mathrm{S}}$ in the section downstream from the weirs, set at $\mathrm{H}_{\mathrm{V}}$ for every corresponding flow $\mathrm{Q}_{\mathrm{V}}$.

Moreover, the compatibility condition according to which the total head $\mathrm{H}_{\mathrm{M}}$ cannot be lower than the total head $\mathrm{H}_{\mathrm{V}}$ must be verified. The theoretical analysis points out a hydraulic jump at the weirs, as is highlighted by the preliminary experimental tests. This analysis was conducted while taking into account the classic relations:

$$
\begin{aligned}
& d H=\left(i_{F}-J\right) \cdot d s=0 \\
& d Q=\mu \cdot \sqrt{2 g} \cdot h_{S}^{3 / 2} \cdot d s
\end{aligned}
$$

where, in addition to the already mentioned symbols and for the $\mathrm{s}$ abscissa, $\mu$ and $\mathrm{h}_{\mathrm{S}}$ indicate the coefficient of discharge and the weir head, respectively, and $\mathrm{J}$ is the unit head loss. In particular, assuming the maximum downstream flow $\mathrm{Q}_{\mathrm{VM}}=14 \mathrm{~m}^{3} / \mathrm{sec}$, the discharged flow $\mathrm{Q}_{\mathrm{SM}}=36 \mathrm{~m}^{3} / \mathrm{sec}$ is the sum of $\mathrm{Q}_{\mathrm{Sv}}=6 \mathrm{~m}^{3} / \mathrm{sec}$, discharged upstream from the hydraulic jump (i.e. in supercritical flow) and of $\mathrm{Q}_{\mathrm{SL}}=30 \mathrm{~m}^{3} / \mathrm{sec}$, discharged downstream from the hydraulic jump (i.e. in subcritical flow). Note that if we fix $\mathrm{Q}_{\mathrm{VM}}=12 \mathrm{~m}^{3} / \mathrm{sec}$, we obtain an excessively long weir due to the lengthening of the spillway section in supercritical flow.

If we fix $Q_{\mathrm{VM}}=16 \mathrm{~m}^{3} / \mathrm{sec}$, we cancel out the weir length in supercritical flow but create conditions of incompatibility for the flow upstream from the weirs. These results can be deduced from the graphs in Fig.2, which report the curves $h(Q)$ and $M(Q)$, for $H=$ const., for the channel in the proximity of the flow regulation device. $M$ generally indicates the total quantity of motion for the generic flow $\mathrm{Q}$, as can be calculated from the well-known equation:

$$
M=h_{G} \cdot \sigma+\frac{Q^{2}}{g \cdot \sigma}
$$

where $\mathrm{h}_{\mathrm{G}}$ is the lowering of the barycentre of the hydraulic section $\sigma$. In actual fact, the presence of the hydraulic jump gives rise to a supercritical flow that gradually decreases downstream but, in accordance with the usual hypotheses, with a total head that is constant and equal to the total head $\mathrm{H}_{\mathrm{M}}$ of the flow immediately upstream from the weirs. On the basis of the same hypotheses, in the subcritical flow section, the flow gradually decreases with a total head constant and equal to the total head $\mathrm{H}_{\mathrm{V}}$ of the flow immediately downstream from the weirs. It is therefore possible to identify the laws according to which the head $\mathrm{h}$ and the total quantity of motion $M$ vary in the channel for the total heads assigned as the flow diminishes In particular, in Fig.2, $\mathrm{h}_{50}$ and $\mathrm{M}_{50}$ indicate the curves corresponding to the total head of the maximum incoming flow $\mathrm{Q}_{\mathrm{MM}}=50 \mathrm{~m}^{3} / \mathrm{sec}$ at the beginning of the device and $\mathrm{h}_{12}$ and $\mathrm{M}_{12}, \mathrm{~h}_{14}$ and $\mathrm{M}_{14}, \mathrm{~h}_{16}$ and $\mathrm{M}_{16}$ respectively indicate the curves corresponding to 
Proc. of the Fourth International Conference on Advances in Civil, Structural and Environmental Engineering - ACSEE 2016. Copyright (C) Institute of Research Engineers and Doctors. All rights reserved. ISBN: 978-1-63248-114-6 doi: 10.15224/ 978-1-63248-114-6-31

the total heads at the end of the device, corresponding to the $\mathrm{Q}_{\mathrm{VM}}$ flows of 12,14 and $16 \mathrm{~m}^{3} / \mathrm{sec}$.

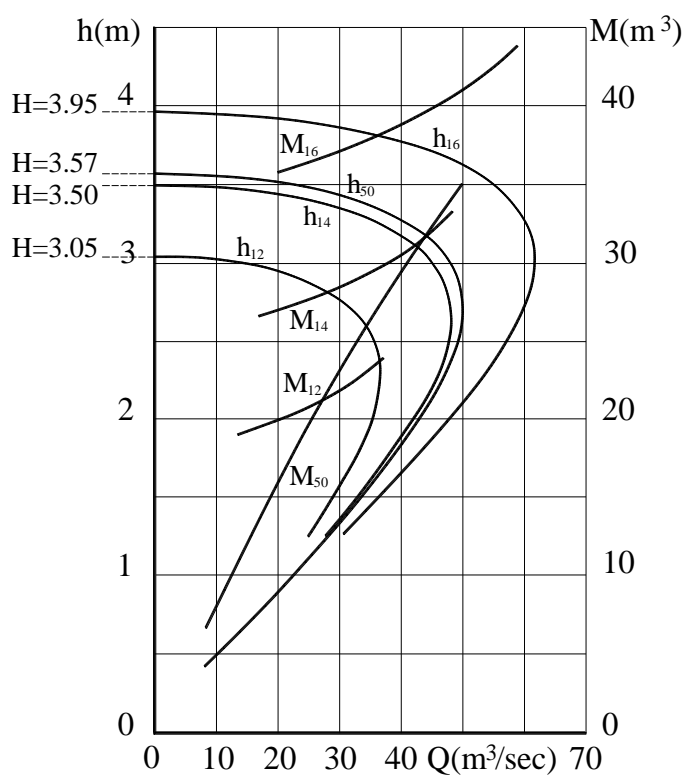

Figure 2. Side Weirs section Curves $h(Q)$ and $M(Q)$ for $H=$ const.

The preliminary experimental tests with the larger flow have shown how the supercritical flow changes to a subcritical flow in the device through a hydraulic jump at an intermediate flow $\mathrm{Q}^{*}$ between $\mathrm{Q}_{\mathrm{Mm}}$ and $\mathrm{Q}_{\mathrm{VM}}$. As this flow $\mathrm{Q}^{*}$ corresponds to one total quantity of motion value $\mathrm{M}$, the flow $Q^{*}$ can be obtained from Fig.2, for instance, at the intersection between the curves $\mathrm{M}_{50}$ and $\mathrm{M}_{12}$ and between the curves $\mathrm{M}_{50}$ and $\mathrm{M}_{14}$ (intersections of the characteristic curves of the supercritical upstream flows and of the subcritical downstream flows). Once $Q^{*}$ has been established, the values $\mathrm{Q}_{\mathrm{MM}}-\mathrm{Q}^{*}$ in the supercritical flow and $\mathrm{Q}^{*}-\mathrm{Q}_{\mathrm{VM}}$ in the subcritical flow can be deduced. As already mentioned, the verification highlights a stretch of the weir in supercritical flow which is too long, for $\mathrm{Q}_{\mathrm{VM}}=12 \mathrm{~m}^{3} / \mathrm{sec}$, and a condition of incompatibility, for $\mathrm{Q}_{\mathrm{VM}}=16 \mathrm{~m}^{3} / \mathrm{sec}$ (the latter condition can be deduced from the curves $M_{50}$ and $M_{16}$ in Fig.2). The results are linked to the geometry of the system and, therefore, it is necessary to modify the measurement section if we want to vary flow regulation.

\section{Iv. Final experimental tests}

Taking into account both the theoretical considerations illustrated above and the first experimental tests, which highlighted the substantial difference between the real flow conditions and the theoretical conditions underlying the usual standards employed when sizing side weirs, the hydraulic layout of the flow regulation device has been modified so that:

- QVM was assigned the value $14 \mathrm{~m}^{3} / \mathrm{sec}$, instead of $12 \mathrm{~m}^{3} / \mathrm{sec}$, and, therefore, $\mathrm{Q}_{\mathrm{SM}}$ was assigned the value $36 \mathrm{~m}^{3} / \mathrm{sec}$ instead of $38 \mathrm{~m}^{3} / \mathrm{sec}$;

the layout which called for side weirs was replaced with one containing orifices whose lower edge height coincided with $\mathrm{Y}_{\mathrm{S}}$ initially assigned to the weir crest.
Thus, in the section in the proximity of the flow regulation device we can hypothesise conditions of subcritical flow with free-water levels which can ensure a sufficient head for the orifices, so that the flow' gradual motion is maintained. Experimental tests have been conducted in various conditions that have highlighted a greater compliance to the theoretical model and the efficiency required. In particular, we have tested orifices with a length measuring $4.90 \mathrm{~m}$ and a height of $0.80 \mathrm{~m}$ and $1.00 \mathrm{~m}$, with a flow $\mathrm{Q}_{\mathrm{M}}=\mathrm{Q}_{\mathrm{S}}=36 \mathrm{~m}^{3} / \mathrm{sec}$ (measurement section closed) and with a flow $Q_{M M}=50 \mathrm{~m}^{3} / \mathrm{sec}$ and $\mathrm{Q}_{\mathrm{SM}}=36 \mathrm{~m}^{3} / \mathrm{sec}$ (measurement section open). In these hypotheses, the flow turned out to be subcritical (as the hydraulic jump is located in the section upstream from the weir) and with gradually varied motion substantially along the whole length of the weirs.

The devices tested are shown in Fig.3-a), which also reports the profiles measured experimentally (dashed lines). Since weirs (especially those in sewers) are often fitted with grills to prevent the passage of solid materials transported in the flow, as has been pointed out above, we have also conducted tests using orifices fitted with a grill which reduces the free-water surface in the ratio 40/55, compared to the initially prescribed size of $\mathrm{L}_{S}=10.00 \mathrm{~m}$. In this case, orifices measuring $0.60 \mathrm{~m}$ and $0.80 \mathrm{~m}$ were tested with a flow $\mathrm{Q}_{\mathrm{SM}}=36 \mathrm{~m}^{3} / \mathrm{sec}$ and the measurement section closed.

The devices tested are also shown in Fig.3-b), along with the experimentally measured profiles. In these tests the flow was likewise subcritical with a hydraulic jump located in the channel section upstream from the weir and with a gradually varied flow along the whole length of the weirs. The motion conditions observed in the model thus lend themselves well to a valid numerical calculation. Indeed, it has been possible to admit:

- gradually varied flow in the channel in the proximity of the flow regulation device;

- a constant total head $\mathrm{H}$ on the flow regulation device of $\mathrm{H}_{\mathrm{S}}=\mathrm{H}_{\mathrm{V}}$ which is determined downstream from the flow regulation device (in the measurement section where the venturi was situated).

Therefore, with known type and dimensions of the orifices, it has been possible to use equations equivalent to (1), (2) and (3) in order to build up the theoretical flow profiles for comparison with the experimentally measured profiles after evaluating the value to attribute to the coefficient of discharge $\mu$ (value again reported in Fig.3) [20-23]. The theoretical profiles are in good agreement with the experimental profiles (the latter are again shown as dashed lines in Fig.3).

A comparison between theoretical and experimental profiles highlights a difference which is very small for the grill and orifice measuring $0.60 \mathrm{~m}$ and which depends on the value assigned to the coefficient of discharge $\mu$. In actual fact there are some differences that are normally positive in the initial section of the device and negative in the final section. This is clearly due to the fact that, unlike the hypothesis introduced into the calculations, the coefficient of discharge $\mu$ of the orifices is not constant but, rather, assumes values that vary gradually along the weir (initially to a small degree and then greater than the adopted average), highlighting the influence of the head value on the coefficient of discharge $\mu$. 
Proc. of the Fourth International Conference on Advances in Civil, Structural and Environmental Engineering - ACSEE 2016. Copyright (C) Institute of Research Engineers and Doctors. All rights reserved.

ISBN: 978-1-63248-114-6 doi: 10.15224/ 978-1-63248-114-6-31

a)

FLOW MEASUREMENT SECTION CLOSED $\mathrm{Q}_{\mathrm{M}}=\mathrm{Q}_{\mathrm{S}}=36 \mathrm{~m}^{3} / \mathrm{sec}$.
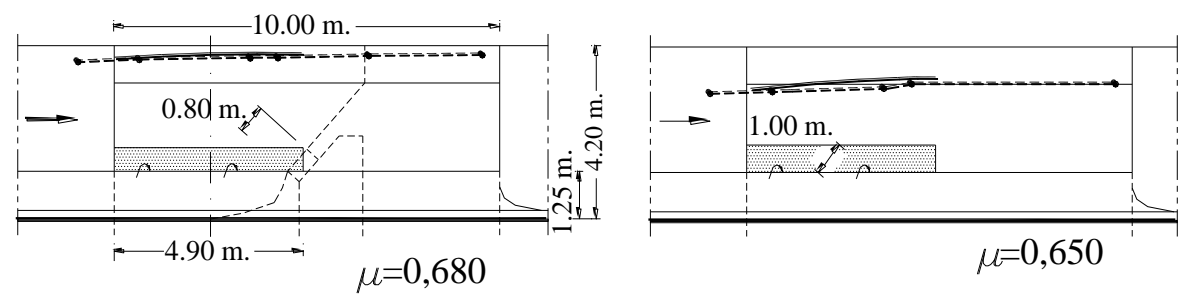

FLOW MEASUREMENT SECTION OPEN $\mathrm{Q}_{\text {MM }}=50 \mathrm{~m}^{3} / \mathrm{sec}$.
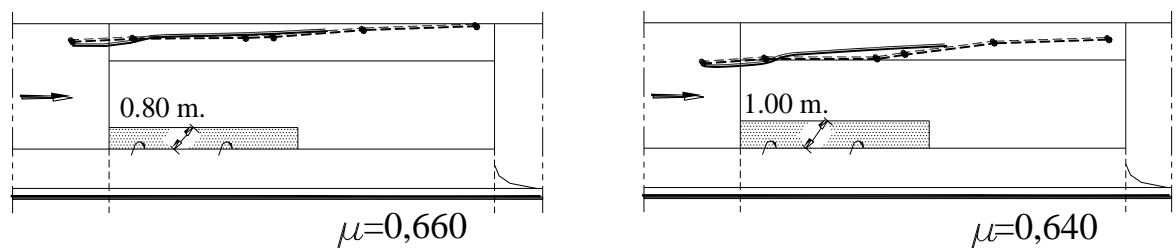

b)

FLOW MEASUREMENT SECTION CLOSED $\mathrm{Q}_{\mathrm{M}}=\mathrm{Q}_{\mathrm{S}}=36 \mathrm{~m} / \mathrm{sec}$.
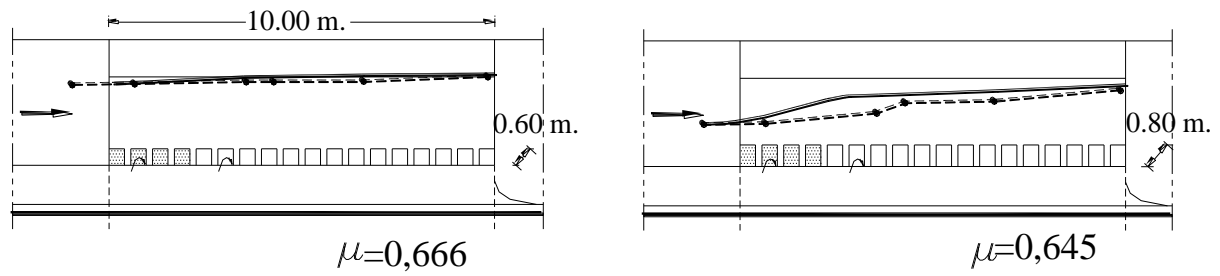

Figure 3. Theoretical and experimental profiles of the modified flow regulation device.

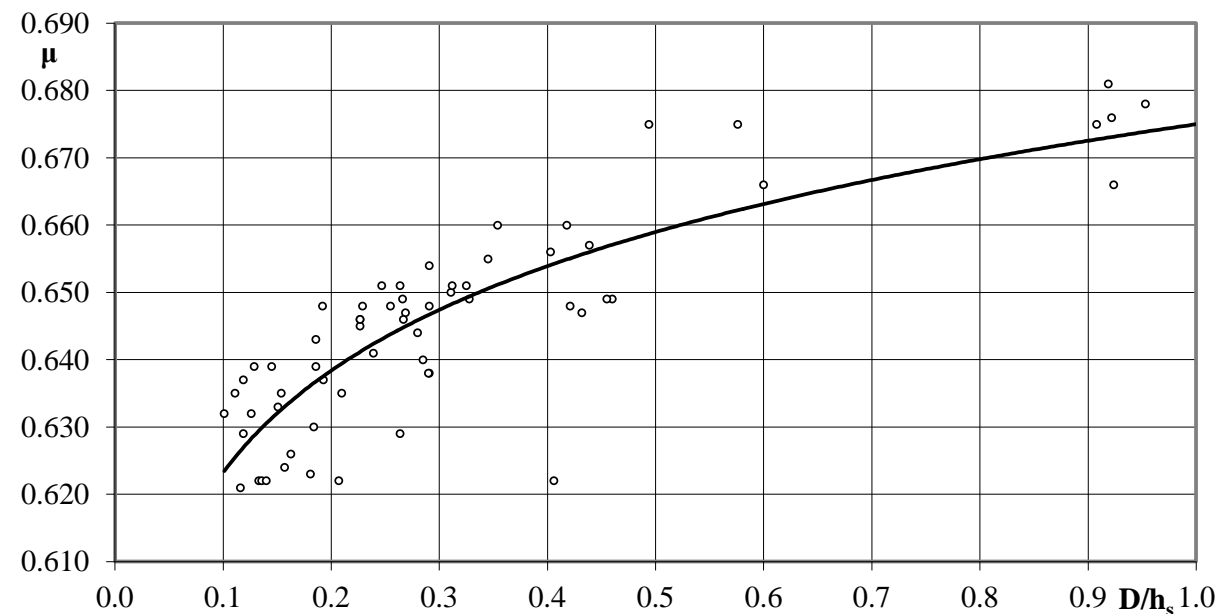

Figure 4. Variation of the coefficient of discharge $\mu$ with $\mathrm{D} / \mathrm{h}_{\mathrm{S}}$. 
Proc. of the Fourth International Conference on Advances in Civil, Structural and Environmental Engineering - ACSEE 2016. Copyright (C) Institute of Research Engineers and Doctors. All rights reserved. ISBN: 978-1-63248-114-6 doi: 10.15224/ 978-1-63248-114-6-31

The experimental results obtained were then processed along with some experimental tests of Carlo Viparelli [24] regarding the values of the coefficients of discharge of orifices in the bottom of a channel and in the presence of a flow parallel to them.

It was thus possible to build the diagram reported in Fig.4 and to verify that the coefficient of discharge $\mu$ varies according to the ratio $\mathrm{D} / \mathrm{h}_{\mathrm{S}}$ between the size of the orifice $\mathrm{D}$ and the head $h_{S}$, for $\mu$ values greater than 0.61 , according to the following equation:

$$
\mu=a \cdot\left(\frac{D}{h_{S}}\right)^{b}
$$

Where the values $\mathrm{a}=0.675$ and $\mathrm{b}=0.0346$ can be assumed. These values are consistent with the experimental results obtained here in subcritical flow (and for values of $\mathrm{D} / \mathrm{h}_{\mathrm{S}}$ between 0.1 and 1.0) enable greater consistency between theoretical and experimental profiles by introducing into the calculations values of $\mu$ that vary with the head.

\section{v. Conclusions}

The analysis and the experimental tests we have conducted stress the importance for side weirs of the hypotheses according to which the head $h_{S}$ on the weir crest must be modest compared to the head in the channel and, conversely it must be considerably larger than the corresponding kinetic head.

Such hypotheses are not often verified in those cases, like the one examined here, in which the flow to be diverted $\mathrm{Q}_{\mathrm{SM}}$ is very close to the maximum flow from upstream $\mathrm{Q}_{\mathrm{MM}}$ : in these conditions, the gradual nature of the motion and the hydrostatic pressure distribution are compromised. Consequently:

- not wishing to forego an operating model which envisages the undisturbed passage of lower flows laden with sewage;

- not wishing to adopt models that call for bottom orifices such as leaping weirs and baffled weirs [1], which are more difficult to control and maintain and are, essentially less efficient;

- for very high $\mathrm{Q}_{\mathrm{SM}} / \mathrm{Q}_{\mathrm{MM}}$ ratios (such as in this case where it is approximately 0.76 )

it is worth adopting a flow regulation device which discharges from orifices (at a height $\mathrm{Y}$ above the bottom line) rather than weirs.

In this case it is possible to reliably build the flow profile in the proximity of the flow regulation device as the motion field can be represented as a gradually varied flow in the longitudinal direction and parallel to the plane of the orifices.

The discharge process, moreover, can be defined through the usual laws on flow through an orifice with coefficients of discharge $\mu$ (variable with ratio $\mathrm{D} / \mathrm{h}_{\mathrm{S}}$ ) that can be evaluated in cases such as the one examined here using equation (4) in the absence of specific experimental values.

\section{References}

[1] V. Biggiero, "Scaricatori a salto per reti di fogne", ANDIS, Ingegneria Sanitaria n.4, 1961 (in italian).

[2] G. De Marchi, "Saggio di teoria del funzionamento degli stramazzi laterali", L'Energia Elettrica, November 1934 (in italian).

[3] H. Rouse, "Verteilung der hydraulischen energie bei einem lotrechten Absturz", Oldendurg, Berlino,1933 (in german).

[4] G.J. Kallwass, "Beitrag zur hydraulischen Berechnung gedrosselter Regenüberläufe", Dissertation TH Karlsruhe, Karlsruhe, 1964 (in german).

[5] M.A. Hamam, J.A. McCorquodale, "Transient conditions in the transition from gravity to surcharged sewer flow", Canadian Journal of Civil Engineering, Vol.9(2), pp. 189-196, 1982.

[6] A. Uyumaz, Y. Muslu, "Flow over side weirs in circular channels", Journal of Hydraulic Engineering, ASCE, Vol.111(1), pp.144-160, 1985.

[7] W.H. Hager, "Lateral outflow over side weirs", Journal of Hydraulic Engineering, ASCE, Vol. 113(4), pp. 491-504, Vol.115(5), pp. 682688, 1987.

[8] W.H. Hager, "Supercritical flow in circular-shaped side weirs", Journal of Irrigation and Drainage Engineering, ASCE, Vol.120(1), pp. 1-12, 1994.

[9] C. Gisonni, W.H. Hager, "Short sewer side weir", Journal of Irrigation and Drainage Engineering, ASCE, Vol.123(5), pp. 354363, 1997.

[10] G. Del Giudice, W.H. Hager, "Sewer side weir with throttling pipe", Journal of Irrigation and Drainage Engineering, ASCE, Vol.125(5), pp. 298-306, 1999.

[11] Y. Muslu, "Lateral weir flow model using a curve fitting analysis", Journalof Hydraulic Engineering, ASCE, Vol. 128 (7). pp. 712-715, 2002.

[12] Y. Muslu, H. Tozluk, E. Yüksel, "Effect of lateral water surface profile on side weir discharge", Journal of Irrigation and Drainage Engineering, ASCE, Vol. 129 (5), pp. 371-375, 2003.

[13] M. Venutelli, "Method of solution of nonuniform flow with the presence of rectangular side weir", Journal of Irrigation and Drainage Engineering, ASCE, Vol. 134(6), pp. 840-846,2008.

[14] O. Castro-Orgaz, W.H. Hager, "Subcritical side weir flow at high lateral discharge", Journal of Hydraulic Engineering, ASCE, Vol.138(9), pp. 777-787, 2012

[15] H. Azimi, H. Hadad, H. Shokati and M. Salimi, "Discharge and flow field of the circular channel along the side weir", Canadian Journal of Civil Engineering, Vol.42(4), pp. 273-280, 2015.

[16] G. Michelazzo, "New analytical formulation of De Marchi's model for a zero-height side weir", Journal of Hydraulic Engineering, ASCE, Vol.141(12), 2015

[17] W.H. Hager, "Impact hydraulic jump", Journal of Hydraulic Engineering, ASCE, Vol.120(5), pp. 633-637, 1994.

[18] A. Balloffet, "Critical flow meters (Venturi flumes)", Proceeding ASCE, Paper n. 743, July 1955.

[19] N. Rajaratnam, N. Muralidhar, "Characteristics of the rectangular free overfall", Journal of Hydraulic Research, Vol. 6, n. 3, 1968.

[20] T. Ishikawa, "Water surface profile of stream with side overflow", Journal of Hydraulic Engineering, ASCE, Vol.110:12, pp. 18301840,1984 .

[21] A. Vatankhah, "New solution method for water surface profile along a side weir in a circular channel." Journal of Irrigation and Drainage Engineering, ASCE, Vol.138(10), pp. 948-954, 2012.

[22] A. Vatankhah, "Water surface profiles along a rectangular side weir in a U-shaped channel (Analytical Findings)." Journal of Hydrologic Engineering, ASCE, Vol.18(5), pp. 595-602, 2013

[23] E. Izadinia, M. Heidarpour, "Discharge coefficient of a circularcrested side weir in rectangular channels." Journal of Irrigation and Drainage Engineering, ASCE, Vol.142(6), 2016.

[24] C. Viparelli, "Dissipatori a griglia di fondo", Proc.Inst. of Hydraulic and Hydraulic Structures, University of Naples, Vol. 148, 1961 (in italian). 